\title{
Mesoscale Eddy Diffusion, Particle Sinking, and the Interpretation of Sediment Trap Data
}

\author{
DAVID A. SIEGEL, ${ }^{1,2}$ TIMOTHY C. GRANATA, $, 3,4$ ANTHONY F. MICHAELS, 1,5 AND TOMMY D. DICKEY 3
}

\begin{abstract}
A Lagrangian analysis of a particle sinking through a random mesoscale eddy field is used to evaluate the effects of horizontal diffusion and particle sinking rates on particulate fluxes sampled by an idealized sediment trap. The analysis indicates that the spatial region where collected particles are formed $\left(L_{x}\right)$ is dependent upon the mean sinking rate of the collected particles and the mesoscale eddy advective field above the trap. This weighted spatial averaging creates difficulties in the interpretation of sediment trap data as fluxes of rapidly sinking particles $\left(>200 \mathrm{~m} \mathrm{~d}^{-1}\right)$ represent local processes $\left(L_{x}<20 \mathrm{~km}\right)$ while fluxes of slower sinking particles $\left(<10 \mathrm{~m} \mathrm{~d}^{-1}\right)$ may be averaged over much larger scales $\left(L_{x}>200 \mathrm{~km}\right)$ for a trap deployed at $1000 \mathrm{~m}$. Several examples of the potential effects that this spatial averaging may have upon the ecological interpretation of the sediment trap collected particle fluxes are presented.
\end{abstract}

\section{INTRODUCTION}

The determination of the vertical flux of particulate material from the euphotic zone to the deep sea is relevant to many biogeochemical questions including: global material budgets, new production of the euphotic zone, and the transformations of materials within intermediate depth waters [e.g., Eppley and Peterson, 1979; Suess, 1980; Brewer et al., 1986]. Fluxes of sinking particles are commonly measured using moored or freely floating sediment traps [e.g., Smetacek et al., 1978; Honjo et al., 1980; Honjo, 1982; Betzer et al., 1984; Takahashi, 1986; Deuser, 1986; Martin et al., 1987; Pace et al., 1987; Deuser et al., 1988]. Although there have been studies of the performance of sediment traps (e.g., a trap's collection efficiency, degradation and grazing of captured materials, resuspension of collected materials, the effects of poisoning, etc.), there has been little discussion devoted to the potential effects of the mesoscale eddy advective motions above the trap in dispersing sinking particles.

Here, a Lagrangian analysis of a particle sinking in a random horizontal eddy field is used to investigate the sampling of particle fluxes. This analysis represents a quantification of the "statistical funnel" that lies above a sediment trap [Deuser et al., 1988]. The results of this analysis relate the effects of the mesoscale eddy field above the sediment trap to the horizontal length scale over which a perfect sediment trap would sample particulate fluxes. These same considerations also apply to the sedimentation of sinking particulate material at the sea floor.

\footnotetext{
${ }^{1}$ Woods Hole Oceanographic Institution, Woods Hole, Massachusetts.

${ }^{2}$ Now at Department of Geography, University of California at Santa Barbara.

${ }^{3}$ Ocean Physics Group, Department of Geological Sciences, University of Southem Califomia, Los Angeles.

${ }^{4}$ Now at Department of Biology, Southeastern Massachusetts University, North Dartmouth.

${ }^{5}$ Now at Bermuda Biological Station for Research, Ferry Reach, Bermuda.
}

Copyright 1990 by the American Geophysical Union.

Paper number 89JC03184.

0148-0227/90/89JC-03184\$05.00
A Lagrangian formulation of fluid motion addresses the motion of a turbulent flow in terms of the trajectories of particles and/or fluid parcels within the flow [Tennekes and Lumley, 1972; Davis, 1983; Bennett, 1987]. Hence, this should be the natural method of addressing the horizontal dispersion of sinking particles in the sea. Lagrangian fluid particle trajectories within intermediate depth waters (roughly $1000 \mathrm{~m}$ ) have been studied using neutrally buoyant SOFAR floats [e.g., Rossby et al., 1975]. The statistical analysis of the dispersion of arrays of SOFAR floats has enabled horizontal particle dispersion characteristics to be addressed [e.g., Freeland et al., 1975; Riser and Rossby, 1983; McWilliams et al., 1983; Rossby et al., 1986; Böning, 1988]. Horizontal dispersion estimates also have been made numerically using an eddy-resolving general circulation model [Böning and Cox, 1988]. Similar Lagrangian techniques have recently been applied to addressing the spatial extent of nearsurface phytoplankton blooms [Bennett and Denman, 1985; 1989]. An excellent introduction to the Lagrangian formulation of turbulent transport is given by Tennekes and Lumley [1972].

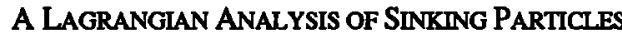

The trajectory (or path) that a particle traverses as it sinks from its formation at the surface to the sediment trap at a depth $H$ may be denoted as $x_{i}(a ; t)$, where $a$ is the location of the sediment trap, the subscript $i$ refers to the $i$ th particle, and $t$ is time (the particle starts sinking at $t=0$ ). Particles that are collected by a trap must have trajectories which coincide at that location; therefore $\mathrm{x}_{i}\left(\mathrm{a} ; T_{i}\right)=\mathrm{a}$, where $T_{i}$ is the time required for the particle to reach the trap. Of course, the time required for different particles to reach the trap may not be the same. The trajectory of the particle can be calculated if the velocity of the particle as it traverses through the ocean is known [Tennekes and Lumley, 1972] or

$$
\mathbf{x}_{i}(\mathbf{a} ; t)+\int_{t}^{T_{i}} \mathbf{v}_{i}\left(\mathbf{a} ; t^{\prime}\right) d t^{\prime}=\mathbf{x}_{i}\left(\mathbf{a} ; T_{i}\right)
$$

where the Lagrangian velocity of the particle $\left(\boldsymbol{v}_{i}(\mathbf{a} ; t)\right)$ includes its intrinsic sinking speed. The Lagrangian velocity of the particle may be expressed in terms of the Eulerian fluid velocity 
(that is, at a fixed point in space) at the instantaneous location of the particle and the particle's sinking velocity by

$$
\mathbf{v}_{i}(\mathbf{a} ; t)=\mathbf{u}\left(\mathbf{x}_{i}(\mathbf{a} ; t), t\right)+s_{i}(t)
$$

where $s_{i}(t)$ is the vertical sinking speed of the $i$ th particle (positive downward) and $\mathrm{u}\left(\mathrm{x}_{i}(\mathbf{a} ; t), t\right)$ is the three-dimensional fluid velocity acting upon the particle along its trajectory. The time required for a particle to sink from its formation at the sea surface to its collection $\left(T_{i}\right)$ at a trap at a depth $H$ may be determined using

$$
H=\int_{0}^{T_{i}}\left[w\left(\mathbf{x}_{i}\left(\mathbf{a} ; t^{\prime}\right), t^{\prime}\right)+s_{i}\left(t^{\prime}\right)\right] d t^{\prime}
$$

To simplify the analysis, we assume that the time average (from 0 to $T_{i}$ ) of the vertical fluid velocity evaluated at the particle $\left(w\left(\mathbf{x}_{i}(\mathbf{a} ; t), t\right)\right)$ is much less than average sinking speed of the particle (see Table 1). This should be a good assumption for the time (1-100 days) and horizontal space $(1-1000 \mathrm{~km})$ scales investigated [e.g., Gill, 1982]. It should be noted that in intense boundary currents, such as the Gulf Stream, vertical velocities of $O\left(100 \mathrm{~m} \mathrm{~d}^{-1}\right)$ have been observed [Bower and Rossby, 1989]. However, the simple analysis presented here cannot pertain to such strong currents and their large horizontal mean shears. Thus the sinking time $\left(T_{i}\right)$ may be calculated by

$$
\begin{aligned}
& H=\int_{0}^{T_{i}} s_{i}\left(t^{\prime}\right) d t^{\prime}=S_{i} T_{i} \\
& T_{i}=H / S_{i}
\end{aligned}
$$

where $S_{i}$ is the mean sinking rate averaged over the time interval 0 to $T_{i}$. That is, $T_{i}$ is the average sinking time for the particle as it traverses from its formation near the sea surface to the trap at depth.

The horizontal distance that a particle has traversed during a time duration $T_{i}$ may be calculated knowing the horizontal fluid velocity acting upon it. For the $x$ component, this distance, $d_{x i}$, for the $i$ th particle is equal to

$$
d_{x i} \equiv x_{i}\left(\mathbf{a} ; T_{i}\right)-x_{i}(\mathbf{a} ; 0)=\int_{0}^{T_{i}} u\left(\mathbf{x}_{i}\left(\mathbf{a} ; t^{\prime}\right), t^{\prime}\right) d t^{\prime}
$$

This quantifies the horizontal distance traversed by an individual particle as simply the summation of the horizontal

\begin{tabular}{|c|c|c|}
\hline Particle Type & $\begin{array}{c}\text { Sinking Rate, } \\
\text { m day }^{-1}\end{array}$ & Reference \\
\hline $\begin{array}{l}\text { Phytoplankton } \\
\text { Ultraplankton } \\
\text { Net plankton } \\
\text { Algal aggregates } \\
\text { Marine snow } \\
\text { Fecal material }\end{array}$ & $\begin{array}{r}<0.1-2 \\
<10-20 \\
40-150 \\
1-368\end{array}$ & $\begin{array}{l}\text { Bienfang }[1980] \\
\text { Smayda }[1970] \\
\text { Smelacek }[1985] \\
\text { Alldredge and Silver }[1988]\end{array}$ \\
\hline $\begin{array}{l}\text { Nauplii and copepidids } \\
\text { Crustacea } \\
\text { Salps }\end{array}$ & $\begin{array}{c}5-28 \\
20-150 \\
450-2700\end{array}$ & $\begin{array}{l}\text { Paffenhofer and Knowles [1979] } \\
\text { Small et al. [1979] } \\
\text { Bruland and Silver [1981] }\end{array}$ \\
\hline
\end{tabular}
currents acting on it. However, it is the horizontal distance that many similar particles (or "cloud" of particles) have dispersed which is of present interest. If the mean fluid velocity is zero, the mean horizontal and vertical velocity shears are zero and the fluctuating components of the

TABLE 1. Characteristic Sinking Rates for Marine Particles horizontal velocity are statistically stationary, the variance of the particle "cloud" distribution may be estimated [Taylor, 1921]. The length scale over which many similar particles (with mean sinking rates $S_{i}$ ) are averaged can be calculated as the root-mean-square value of $d_{x i}$ (denoted here as $L_{x}$ ) or

$$
L_{x}=u^{\prime}\left(2 \int_{0}^{T_{i} t^{\prime}} R_{x x}(\tau) d \tau d t^{\prime}\right)^{1 / 2}
$$

where $u^{\prime}$ is the magnitude of the horizontal velocity fluctuations associated with the mesoscale eddy field (averaged over the sinking time, $\left.T_{i}\right)$, and $R_{x x}(\tau)$ is the Lagrangian velocity autocorrelation function $\left(R_{x x}(\tau) \equiv\left\langle u(\mathbf{a} ; t) u(\mathbf{a} ; t+\tau)>/ u^{\prime 2}\right.\right.$; where the angle brackets denote averaging over an ensemble of similar fluid parcels). The Lagrangian autocorrelation function quantifies the degree to which a fluid parcel's horizontal velocity component is correlated with itself as a function of the time lag. Several examples of Lagrangian autocorrelation functions calculated from the dispersion of SOFAR float arrays deployed in the North Atlantic Ocean are shown in Figure 1.

It should be stressed that the length scale ( $L_{x}$; equation (6)) quantifies the statistical distribution (i.e., a normal distribution) of particles collected by the trap. That is, $65 \%$ of the collected particles with mean sinking rates equal to $S_{i}$ will have been created within a horizontal distance of $L_{x}$ from the trap. Approximately $95 \%$ of the particles sampled by an idealized trap have originated from within a horizontal distance of $2 L_{x}$ from the trap.

The integral time scale of the Lagrangian autocorrelation function $\left(\tau_{x x}\right)$ is a natural time scale for characterizing the structure of $R_{x x}(\tau)$ and is expressed as

$$
\tau_{x x}=\int_{0}^{\infty} R_{x x}(\tau) d \tau
$$

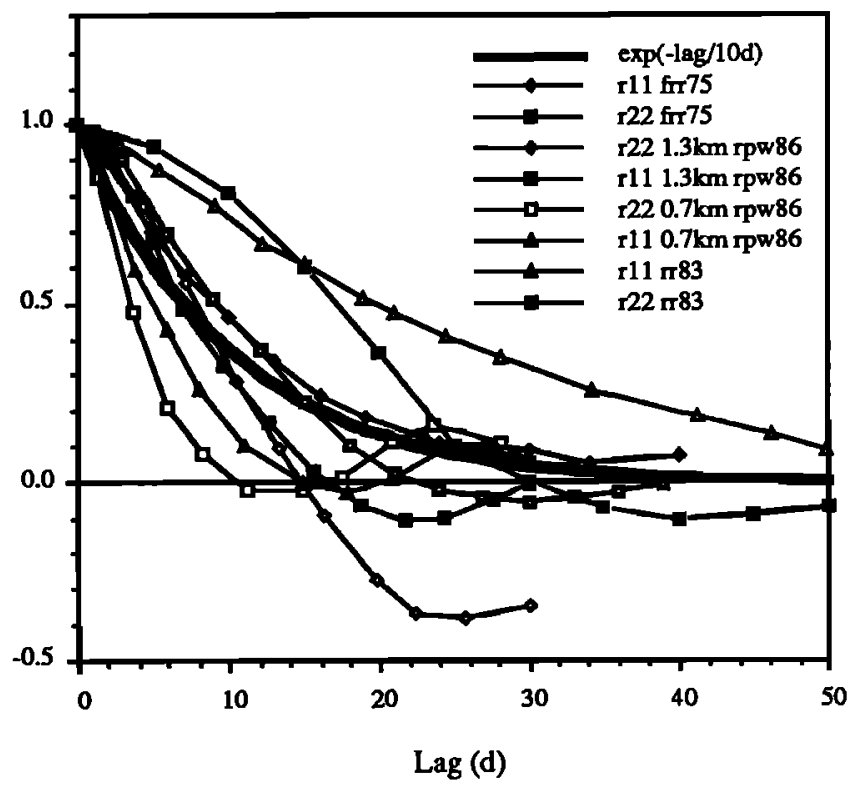

Fig. 1. Lagrangian autocorrelation functions calculated from the dispersion of SOFAR floats within the western North Atlantic Ocean at intermediate depths $(700$ to $1300 \mathrm{~m})$. The $R_{11}(\tau)\left(\equiv R_{x x}(\tau)\right)$ is the Lagrangian autocorrelation function in the zonal direction and $R_{22}(\tau)$ $\left(\equiv R_{y y}(\tau)\right.$ ) in the meridional direction. FRR75 is Freeland et al. [1975], RR83 is Riser and Rossby [1983]; and RPW86 is Rossby et al. [1986]. The heavy solid line is the exponential form $(R(\tau)=\exp (-\tau / 10$ days $))$. 
The Lagrangian integral scale $\left(\tau_{x x}\right)$ quantifies the decorrelation time scale of a fluid parcel's horizontal velocity with itself. Values of the Lagrangian integral scale calculated using SOFAR floats deployments vary from about 5 to 18 days [Freeland et al., 1975; Riser and Rossby, 1983; Rossby et al., 1986; Böning, 1988] and a value of 10 days is thought to be typical [McWilliams et al., 1983]. There appears to be some evidence of directional, vertical, temporal, and geographic variability in the values of $\tau_{x x}$ [Böning, 1988]; however, a value of 10 days is likely to be representative for much of the oceanic interior.

The time required for the particle to sink to the trap relative to the Lagrangian integral time scale may be used to simplify the evaluation of equation (6). For sinking times $\left(T_{i}\right)$ much smaller than $\tau_{x x}$, the value of $R_{x x}(\tau)$ is approximately equal to 1 ; and equation (6) may be evaluated as

$$
L_{x} \cong u^{\prime} T_{i} \quad T_{i} \ll \tau_{x \alpha}
$$

This expression quantifies the collection of rapidly sinking particles (mean sinking rates, $S_{i}$, much greater than $100 \mathrm{~m} \mathrm{~d}^{-1}$ for a 1000-m trap and $\tau_{x x}=10$ days). It should be noted that for these rapidly sinking particles, the collection distance increases linearly with sinking time. For sinking times that are much larger than the Lagrangian integral scale, equation (6) is equal to

$$
L_{x} \cong u^{\prime} \sqrt{2 \tau_{x x} T_{i}} \quad T_{i} \gg \tau_{x x}
$$

This expression should quantify the collection scale for comparatively slowly sinking particles $\left(S_{i} \ll 100 \mathrm{~m} \mathrm{~d}^{-1}\right.$ for a 1000-m trap). Thus the spatial averaging scale should increase with the square root of the time required for these slowly sinking particles to reach the trap.

\section{EVAlUation of the SPatial AVERaging SCALE}

Sinking rates for typical marine particles vary from 0.1 to $2700 \mathrm{~m} \mathrm{~d}^{-1}$ (see Table 1). For a trap deployed at $1000-\mathrm{m}$, these sinking rates correspond to mean sinking times of 0.4 to 10000 days. These sinking times can be much greater or much less than typical Lagrangian integral time scales $\left(\tau_{x x} \cong 10\right.$ days) depending upon the type of particle and the depth of the trap. This means that the approximate evaluation of the spatial averaging scale $\left(L_{x}\right)$ using either equations (8) or (9) will not be valid for all marine particles. The proper estimation of $L_{x}$ requires that the double integral in equation (6) be solved for typical Lagrangian autocorrelation functions.

The direct evaluation of the spatial averaging scale requires that an assumption of the average structure of the horizontal Lagrangian autocorrelation function $\left(R_{x x}(\tau)\right)$ for the ocean be made. A collection of $R_{x x}(\tau)$ (and $R_{y y}(\tau)$ ) functions calculated from the dispersion of SOFAR floats within the intermediate depths of the North Atlantic Ocean is shown in Figure 1. Also shown in Figure 1 is an exponential analytic form $\left(R_{x x}(\tau)=\right.$ $\exp \left(-\tau / \tau_{x x}\right)$, where $\tau_{x x}$ is equal to 10 days). Horizontal averaging scales $\left(L_{x}\right)$ were calculated using each of the Lagrangian autocorrelation functions displayed in Figure 1. Differences among all of the resulting length scales were at most a factor of 3 , scattered about the results found using the exponential form. Thus the exponential analytic form will be used in the following discussions. The exponential form for $R_{x x}(\tau)$ enables $L_{x}$ to be evaluated in a convenient closed form.

$$
L_{x}=u^{\prime} \sqrt{2}\left\{\tau_{x x} T_{i}-\tau_{x x}^{2}\left[1-\exp \left(-T_{i} \tau_{x x}\right)\right]\right\}^{1 / 2}
$$

This expression enables the horizontal averaging scale to be calculated in terms of the magnitude of the horizontal velocity fluctuations $\left(u^{\prime}\right)$, the mean sinking time $\left(T_{i}\right)$, and the Lagrangian integral time scale $\left(\tau_{x x}\right.$, which is assumed to be equal to 10 days).

Horizontal velocity fluctuations can be expressed in terms of the eddy kinetic energy per unit mass $\left(K_{E}\right.$, where $\left.u^{\prime 2}=2 K_{E}\right)$. The eddy kinetic energy describes the amplitude of horizontal kinetic energy variations on temporal scales ranging from two days to annual time scales [e.g., Dickson, 1983]. Direct determinations of the eddy kinetic energy give values of 100 $1000 \mathrm{~cm}^{2} \mathrm{~s}^{-2}$ near the sea surface and values of $1-10 \mathrm{~cm}^{2} \mathrm{~s}^{-2}$ at 1000-m depth [Schmit2, 1978, 1984; Dickson, 1983]. For depths between 100 and $2000 \mathrm{~m}$, a value of $K_{E}$ of $10 \mathrm{~cm}^{2} \mathrm{~s} \mathrm{~s}^{-2}$ is fairly representative [Dickson, 1983]. Applying the definition of $K_{E}$ to equation (10), $L_{x}$ is found to be equal to

$$
L_{x}=2 \sqrt{K_{E}}\left\{\tau_{x x} T_{i}-\tau_{x x}^{2}\left[1-\exp \left(-T_{i} / \tau_{x x}\right)\right]\right\}^{1 / 2}
$$

Values of the spatial averaging scale $\left(L_{x}\right)$ for different values of the eddy kinetic energy and the mean sinking rate are shown in Figure $2 a$ for a trap deployed at $1000-\mathrm{m}$ and in Figure $2 b$ for a 4000-m deployment.

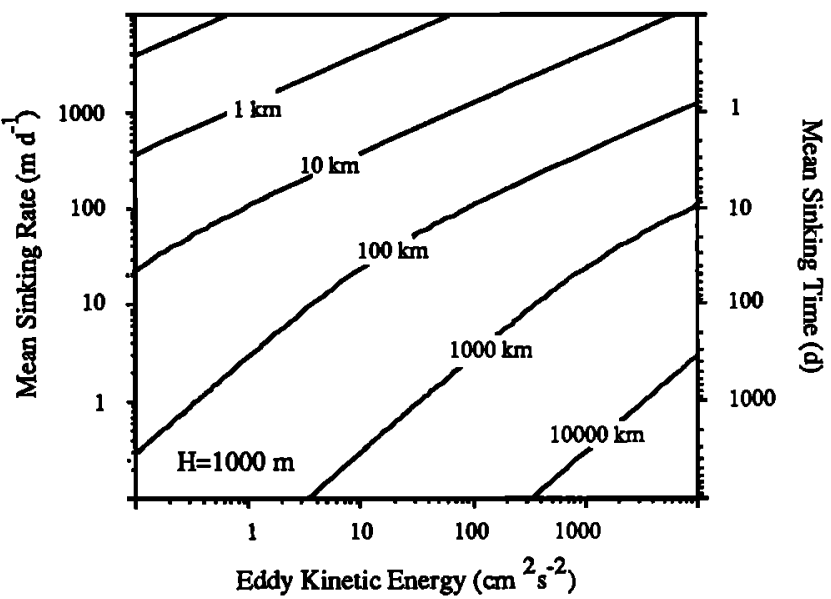

Fig. 2a. Horizontal averaging scale ( $L_{x}$ in kilometers) as a function of mean eddy kinetic energy $\left(K_{E}\right)$ and mean sinking rate $\left(S_{i}\right)$ for a sediment trap deployed at $1000-\mathrm{m}$. The mean sinking time $\left(T_{i}\right)$ is also shown.

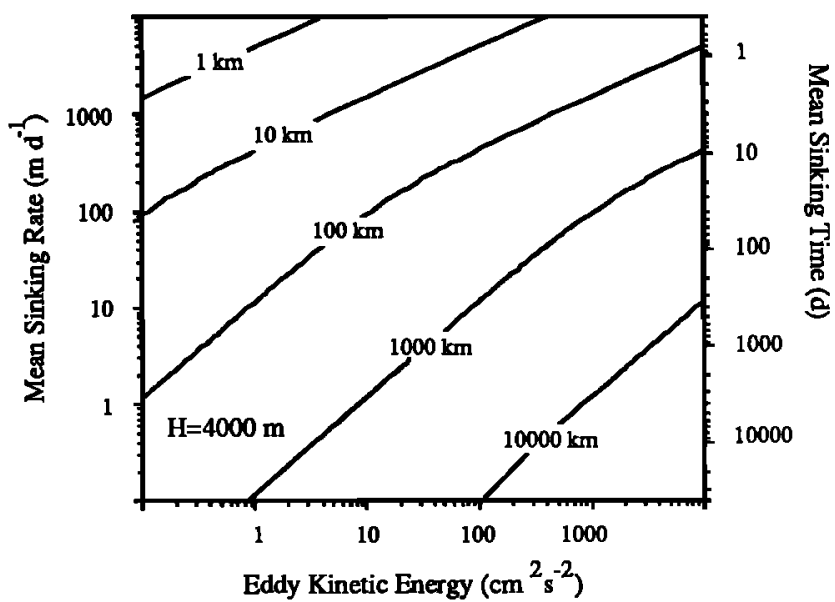

Fig. 2b. Horizontal averaging scale ( $L_{x}$ in kilometers) as a function of mean eddy kinctic energy $\left(K_{E}\right)$ and mean sinking rate $\left(S_{i}\right)$ for a trap deployed at 4000-m. 
Using a representative intermediate depth value of $K_{E}$ of 10 $\mathrm{cm}^{2} \mathrm{~s}^{-2}$ and the range of particle sinking rates for the different marine particles presented in Table 1 (from 0.5 to $2000 \mathrm{~m} \mathrm{~d}^{-1}$ ), the horizontal averaging scale ranges from 2 to $800 \mathrm{~km}$ for a trap deployed at $1000-\mathrm{m}$ and from 8 to $1500 \mathrm{~km}$ for a trap deployed at 4000 -m (Figures $2 a$ and $2 b$ ). An ideal sediment trap at $1000-\mathrm{m}$ will collect a sample of the entire spectrum of sinking particles at that depth, a combination of both rapidly sinking and slowly sinking particles. The rapidly sinking particles, with small averaging scales, will have been produced locally, directly above the trap. In contrast, fluxes of the slowly sinking particles will be averaged over large geographic distances, and the conditions above the trap may not be representative of the environment in which the particles were originally formed. At the sea floor (that is, at depths of roughly $4000 \mathrm{~m}$ ), very slowly sinking particles will have horizontal averaging scales approaching the dimensions of the oceanic basins (thousands of kilometers; Figure $2 b$ ).

\section{INTERPRETING SEDIMENT TRAP COMPOSITION DATA}

Vertical fluxes of particulate matter as measured by sediment traps are usually interpreted by comparison with various water column measurements (e.g., production, phytoplankton stocks, etc.) made at the same geographic location. From these comparisons, researchers have proposed various functional relationships between primary production, depth, and the magnitude of the sinking exports [e.g., Suess, 1980; Betzer et al., 1984; Pace et al., 1987; Martin et al., 1987]. The mechanisms that create and alter sinking particles are inferred from a detailed examination of the composition of the particulate matter in the traps. The elemental composition leads to inferences about the relative importance of carbonateversus silicate-bearing plankton, the magnitude of terriginous and aeolian inputs, etc. [e.g., Honjo, 1982]. Pigment concentrations of collected particulate materials from traps have been used to elucidate the relative importance of metazoan and microplankton grazing in the creation of sinking particles and their subsequent transformations [Welschmeyer and Lorenzen, 1986]. The microscopic examination of trap material can identify specific organisms or processes that may be disproportionately important in export processes (e.g., the sinking of large algae after a bloom, fluxes of marine snow, the relative importance of metazoan grazer fecal pellets, etc.).

The Lagrangian analysis described above indicates that the relationship between suspended particle pools at a location and the sinking fluxes at depth will be modified by the random mesoscale eddy field through which the particles sink. The average sinking speed of sinking particulate matter collected by sediment traps has ranged from 60 to $200 \mathrm{~m} \mathrm{~d}^{-1}$ [Honjo, 1982; Takahashi, 1986; Deuser, 1986]. The length scale associated with these sinking rates is $15-60 \mathrm{~km}$ for a trap at $1000-\mathrm{m}$ and $60-120 \mathrm{~km}$ for a trap at $4000-\mathrm{m}$ (Figure 2) for a value of $K_{E}$ of $10 \mathrm{~cm}^{2} \mathrm{~s}^{-2}$. Consequently, primary production rates and phytoplankton standing stocks measured at the trap location should be qualified by the extent to which they represent the average conditions over spatial scales of tens to hundreds of kilometers.

These considerations become more serious for the interpretation of specific components of sinking particulate matter. Sinking rates of the particulate matter collected by traps vary from $<0.1$ to several thousand meters per day (Table 1). Biogenic carbonates and silicates frequently represent a large fraction of total mass fluxes in the deep sea [Honjo, 1982; Deuser, 1986]. Carbonate fluxes are derived primarily from the sinking of the skeletons of coccolithophorids, foraminifera, and pteropods. It is likely that the length scale associated with the sinking of coccoliths (especially when they are not aggregated) will be much larger than those associated with foraminifera and pteropods, which have more rapid settling velocities. Likewise, there will be major differences in the length scales associated with silica fluxes by different species of diatom or by different settling mechanisms (e.g., the settling of single cells versus large aggregates of cells). Fine (slowly sinking) lithogenic material collected in mid-ocean traps may have length scales of hundreds to thousands of kilometers.

Most of the organic matter in sediment traps is found in the form of flocculent aggregates, which is commonly referred to as "marine snow" [Alldredge and Silver, 1988]. These particles have a wide range of sinking speeds (Table 1), and Asper [1987] has shown that they can be advected hundreds of kilometers horizontally. Slowly sinking aggregates $(1-35 \mathrm{~m}$ $\mathrm{d}^{-1}$ [Asper, 1987]) would have length scales of $100-500 \mathrm{~km}$ (for a trap at $1000-\mathrm{m}$ ). The sources of slowly sinking aggregates are diverse and poorly known. Large spatial scales associated with their collection in the deep sea will further confound any correlation between sources in the surface ocean and fluxes in the deep sea.

Fecal pellets are a conspicuous, although usually minor, component of the trap collected materials [Urrere and Knauer, 1981; Pilskan and Honjo, 1987; M. W. Silver and M. M. Gowing, The "particle flux": Origins and biological components, submitted to Progress in Oceanography, 1989, hereinafter referred to as Silver and Gowing, submitted], although it is sometimes possible to identify the organism that creates a specific kind of pellet. For salp fecal pellets in deep traps, the length scales associated with their deposition are small because of their rapid settling velocities. Therefore it is likely that the surface population of salps at the trap location does represent the source of the sinking pellets. However, most fecal pellets have settling rates of $5-150 \mathrm{~m} \mathrm{~d}^{-1}$ (Table 1) and hence length scales of tens to hundreds of kilometers. Zooplankton abundances also exhibit patchiness in their abundance on this scale [e.g., Haury et al., 1978]. Thus there may be little relationship between the surface populations of metazoa and the composition of the surface-derived fecal pellets in deep sea sediment traps.

Patches of high plankton abundance or biological activity (i.e., blooms) are a common feature in the surface waters of many ocean systems. Localized patches of high particulate exports may arise from such near-surface blooms (e.g., post phytoplankton bloom algal settlement, fecal pellet fluxes from salp or crustacean swarms, etc.). The mesoscale eddy field that disperses the sinking particles will have major effects upon the measurement of particle fluxes. If the sediment trap array is located directly beneath the bloom (as might happen in a study specifically designed to study such an event), the particle export will appear to decrease with depth (Figure $3 a$ ). Conversely, if the trap is located away from the event, the sinking particles will begin appearing in the trap at depth (Figure $3 b$ ). Such patterns are frequently found in vertical profiles of sinking flux. Silver and Gowing (submitted) report a gradual increase in the sinking fluxes with depth of a coastal diatom, Skeletonema, in an offshore sediment trap array, even though this diatom was not found in the surface waters. At 


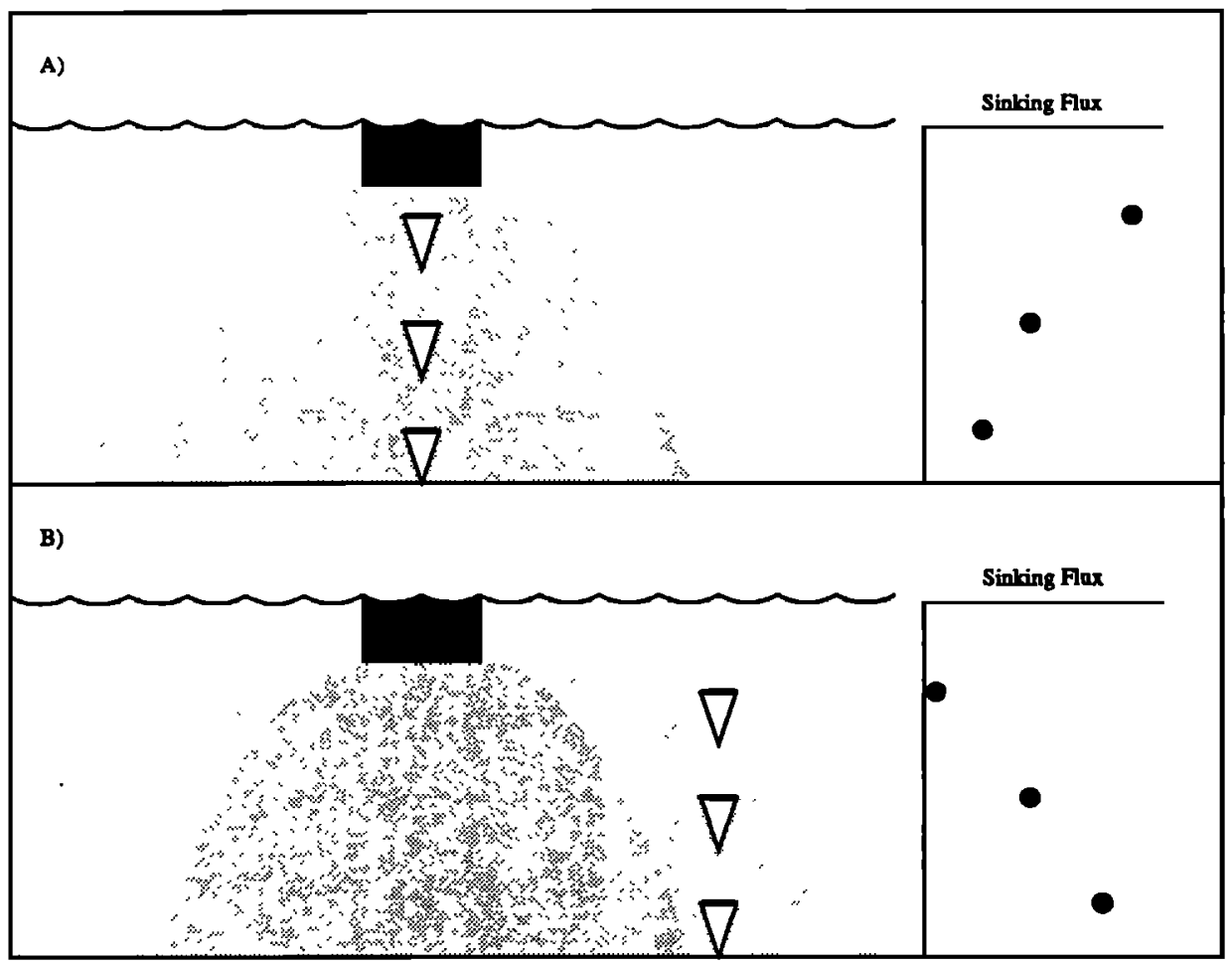

Fig. 3. Conceptual relationship between the location of a sediment trap array and a localized near-surface bloom of sinking particles and the resulting particle fluxes measured by the trap anray. (a) A trap array located directly beneath the near-surface bloom. (b) A trap array located near the bloom, but not directly beneath it.

ocean weather station Papa $\left(50^{\circ} \mathrm{N}, 145^{\circ} \mathrm{W}\right)$, fluxes of individual species of diatoms are frequently higher at $3800 \mathrm{~m}$ than at 1000 m [Takahashi, 1986]. Thus mesoscale eddy diffusion of sinking particles cannot be ignored either in the design of sediment trap experiments or in their subsequent interpretation.

\section{Discussion}

The preceding discussion does not consider vertical variations in either sinking rates $\left(S_{i}\right)$, eddy kinetic energy $\left(K_{E}\right)$, or Lagrangian integral time scale $\left(\tau_{x x}\right)$. Sinking rates of phytoplankton cells depend not only on the size, shape, and composition of the cells but also upon the physiological state of the cells [e.g., Granata, 1987]. It is likely that phytoplankton cells change physiologically or die as they sink through the aphotic zone. As particles settle into the more dense, deep sea, their sinking rates will change as the density contrast between the particle and sea water is reduced. However, it is the mean $S_{i}$ and $K_{E}$, calculated over the path of the sinking particle, which determine the extent over which particle fluxes will be sampled.

Particle aggregation, breakup, consumption, and transformation processes occur at all depths and frequently result in changes in the settling rate or disappearance of the particle class altogether [Urrere and Knauer, 1981; Alldredge and Silver, 1988]. Particle fragmentation followed by repackaging may significantly increase the residence time of material in the deep sea. Therefore midwater particle transformation processes would act to increase the spatial averaging scale of the collected material far beyond values expected for the most rapidly sinking particles. These considerations are most important for the interpretation of elemental fluxes of geochemical tracers.

The eddy kinetic energy $\left(K_{E}\right)$ varies both vertically (with the highest values at the surface) and horizontally (where higher values are found for regions with intense currents [e.g., Wyrtki et al., 1976; Dickson, 1983]). If the particle spends more time in regions of higher $K_{E}$ (i.e., near the sea surface) the extent of the spatial averaging scale would increase above the value calculated above. Conversely, if the particle would spend less time closer to the sea surface, the averaging scale would be less than the present estimates.

The horizontal advection of particles by mean currents (i.e., gyre circulations, boundary currents, localized convergences or upwelling sites, etc.) can also strongly influence the motion of a sinking particle. For example, sinking particles will be advected in a vertically uniform mean current $\left(U=1 \mathrm{~cm} \mathrm{~s}^{-1}\right)$ a distance of over $800 \mathrm{~km}$ for a mean sinking speed of $1 \mathrm{~m} \mathrm{~d}^{-1}$ and about $8 \mathrm{~km}$ for an $S_{i}$ of $100 \mathrm{~m} \mathrm{~d}^{-1}$ (at a $1000-\mathrm{m}$ trap). The mean advection of particulate material must be considered; however, these processes to not act to disperse the particulate field. The combination of eddy diffusion and mean advection would produce a horizontally tilted conelike spatial region over which the trap will sample particle fluxes. It is simple to create scenarios where a trivial fraction of the particles collected by a trap will have been formed locally. This quantification cannot be made rigorously using the simple analysis presented; however, detailed eddy resolving general circulation model simulations could be used for this purpose [e.g., Böning and Cox, 1988].

The present analysis does not apply quantitatively to the sampling of fluxes from free-drifting sediment traps. This is because a large portion of the horizontal velocity structure of 
the mesoscale eddy field is barotropic (that is, the horizontal velocity variations are generally vertically uniform [Gill, 1982]). Thus as the mesoscale eddies advect and diffuse particles, they affect the drifting sediment trap in a similar manner. This suggests that the present spatial averaging scale values should be an overestimate of the scale sampled by drifting traps. However, free-drifting sediment traps would be advected (on the average) towards regions of higher horizontal convergences. This in turn would cause particles to be advected toward the traps, increasing the distance from which the collected particles have originated. The evaluation of the effect of these two competing processes is beyond the scope of the present work.

The present results suggest that the interaction of horizontal advective motions with sinking particles should be considered in the interpretation of sediment trap sensed particulate fluxes. Variations in particle sinking rates for different size particles complicates the ecological interpretation of the sensed fluxes. The proper interpretation of sediment trap data, as well as the deposition of sedimenting materials at the sea floor, requires not only the analyses of material found in the trap but also knowledge of the history of the particles prior to their collection and the flow through which they traversed.

Acknowledgments. Discussions with Werner Deuser, Al Hermann, Burt Jones, Julie Siegel, and Libe Washbum were helpful. DAS and AFM were supported as postdoctoral fellows at the Woods Hole Oceanographic Institution. TCG and TDD were supported by the Office of Naval Research under contract N00014-86-K-0084. Woods Hole Oceanographic Institution contribution 7118. Biowatl contribution 39.

\section{REFERENCES}

Alldredge, A. L., and M. W. Silver, Characteristics, dynamics and significance of marine snow, Prog. Oceanogr., 20, 41-82, 1988.

Asper, V. L., Measuring the flux and sinking speeds of marine snow aggregates, Deep Sea Res., 34, 1-17, 1987.

Bennett, A. F., A Lagrangian analysis of turbulent diffusion, Rev. Geophys., 25, 799-822, 1987.

Bennett, A. F., and K. L. Denman, Phytoplankton patchiness inferences from particle statistics, J. Mar. Res., 43, 307-335, 1985.

Bennett, A. F., and K. L. Denman, Large-scale patchiness due to an annual plankton cycle, J. Geophys. Res., 94, 823-829, 1989.

Betzer, P. R., W. J. Showers, E. A. Laws, C. D. Winn, G. R. DiTullio, and P. M. Kroopnick, Primary production and particle flux on a transect of the equator at $153^{\circ} \mathrm{W}$ in the Pacific Ocean, Deep Sea Res., $31,1-11,1984$.

Bienfang, P. K., Phytoplankton sinking rates in oligotrophic waters off Hawaii, USA, Mar. Biol., 61, 69-77, 1980.

Böning, C. W., Characteristics of particle dispersion in the North Atlantic: an alternative interpretation of SOFAR float results, Deep Sea Res., 35, 1379-1385, 1988.

Böning, C. W., and M. D. Cox, Particle dispersion and mixing of conservative properties in an eddy-resolving model, J. Phys. Oceanogr., 18, 320-338, 1988.

Bower, A. S., and T. Rossby, Evidence of cross-frontal exchange processes in the Gulf Stream based on isopycnal RAFOS float data, $J$. Phys. Oceonogr., 19, 1177-1190, 1989.

Brewer, P. G., K. W. Bruland, R. W. Eppley, and J. J. McCarthy, The Global Ocean Flux Study (GOFS): Status of the U.S. GOFS program, Eos Trans. AGU, 67, 827-832, 1986.

Bruland, K. W., and M. W. Silver, Sinking rates of fecal pellets from gelatinous zooplankton (salps, pteropods, doliolids), Mar. Biol., 63, 295-300, 1981.

Davis, R. E., Oceanic property transport, Lagrangian particle statistics, and their prediction, J. Mar. Res., 41, 163-194, 1983.

Deuser, W. G., Seasonal and interannual variations in deep-water particle fluxes in the Sargasso Sea and their relation to surface hydrography, Deep Sea Res., 33, 225-246, 1986.
Deuser, W. G., F. E. Muller-Karger, and C. Hemleben, Temporal variations of particle fluxes in the deep subtropical and tropical North Atlantic: Eulerian versus Lagrangian effects, J. Geophys. Res., 93, 6857-6862, 1988.

Dickson, R. R., Global summaries and intercomparisons: Flow statistics from long-term current meter moorings, in Eddies in Marine Science, edited by A. R. Robinson, pp. 278-353, Springer-Verlag, New York, 1983.

Eppley, R. W., and B. J. Peterson, Particulate organic matter flux and planktonic new production in the deep ocean, Nature, 282, 677-680, 1979.

Freeland, H. J., P. B. Rhines, and H. T. Rossby, Statistical observations of the trajectories of neutrally buoyant floats in the North Atlantic, J. Mar. Res., 33, 383-404, 1975.

Gill, A. E., Atmosphere-Ocean Dynamics., 662 pp., Academic, San Diego, Calif., 1982.

Granata, T. C., Measurements of phytoplankton sinking and growth under varied light intensities and mixing regimes, Ph.D. dissertation, 175 pp., Univ. of Calif., Berkeley, 1987.

Haury, L. R., J. A. McGowan, and P. H. Wiebe, Pattems and processes in the time-space scales of plankton distributions, in Spatial Patterns in Plankton Communities, edited by J. H. Steele, pp. 277-327, Plenum, New York, 1978.

Honjo, S., Seasonality and interaction of biogenic and lithogenic particulate flux at the Panama Basin, Science, 218, 883-884, 1982.

Honjo, S., J. F. Connell, and P. L. Sachs, Deep-ocean sediment trap; design and function of PARFLUX Mark II, Deep Sea Res., 27, 745753, 1980.

Martin, J. H., G. A. Knauer, D. M. Karl, and W. W. Broenkow, VERTEX: Carbon cycling in the northeast Pacific, Deep Sea Res., 34, 267-285, 1987.

McWilliams, J. C., E. D. Brown, H. L. Bryden, C. C. Ebbesmeyer, B. A. Elliott, R. H. Heinmiller, Bach Lien Hua, K. D. Leaman, E. J. Lindstrom, J. R. Luyten, S. E. McDowell, W. B. Owens, H. Perkins, J. F. Price, L. Regier, S. C. Riser, H. T. Rossby, T. B. Sanford, C. Y. Shen, B. A. Taft and J. C. Van Leer, The local dynamics of eddies in the westem North Atlantic, in Eddies in Marine Science, edited by A R. Robinson, pp. 92-113, Springer-Verlag, New York, 1983.

Pace, M. L., G. A. Knauer, D. M. Karl, J. H. Martin, Primary production, new production and vertical flux in the eastem Pacific Ocean, Nature, 325, 803-804, 1987.

Paffenhofer, G. A., and S. C. Knowles, Ecological implications of fecal pellet size, production and consumption by copepods, J. Mar. Res., $37,3549,1979$.

Pilskan, C. H., and S. Honjo, The fecal pellet fraction of biogeochemical particle flux to the deep sea, Global Biogeochem. Cycles, 1, 31-48, 1987.

Riser, S. C., and H. T. Rossby, Quasi-Lagrangian structure and variability of the subtropical North Atlantic circulation, J. Mar. Res., 41, 127-162, 1983.

Rossby, H. T., A. D. Voorhis, and D. Webb, A quasi-Lagrangian study of mid-ocean variability using long-range SOFAR floats, J. Mar. Res., 33, 355-382, 1975.

Rossby, T., J. Price, and D. Webb, The spatial and temporal evolution of a cluster of SOFAR floats in the POLYMODE Local Dynamics Experiment (LDE). J. Phys. Oceanogr., 16, 428442, 1986.

Schmitz, W. J., Jr., Observations of the vertical structure of low frequency kinetic energy in the westem North Atlantic, J. Mar. Res., $36,295-310,1978$.

Schmitz, W. J., Jr., Observations of the vertical structure of the eddy field in the Kuroshio extension, J. Geophys. Res., 89, 63556364, 1984.

Small, L. F., S. W. Fowler and M. Y. Unlu, Sinking rates of natural copepod fecal pellets, Mar, Biol., S1, 233-241, 1979.

Smayda, T. J., The suspension and sinking of phytoplankton in the sea, Oceanogr. Mar. Biol. Annu. Rev., 8, 353414, 1970.

Smetacek, V. S., Role of sinking diatom life-history cycles: Ecological, evolutionary and geological significance, Mar. Biol., 84, 239-251, 1985.

Smetacek, V., K. von Bröckel, B. Zeitzschel, and W. Zenk, Sedimentation of particulate matter during a phytoplankton spring bloom in relation to the hydrographical regime, Mar. Biol., 47, 211226, 1978.

Suess, E., Particulate organic carbon flux in the oceans-surface productivity and oxygen utilization, Nature, 288, 260-263, 1980. 
Taylor, G. I., Diffusion by continuous movements, Proc. London Math. Soc., 20, 196-212, 1921.

Takahashi, K., Seasonal fluxes of pelagic diatoms in the subarctic Pacific, 1982-1983, Deep Sea Res., 33, 1225-1251, 1986.

Tennekes, H., and J. L. Lumley, A First Course in Turbulence, 300 pp., MIT Press, Cambridge, Mass., 1972.

Urrere, M. A., and G. A. Knauer, Zooplankton fecal pellet fluxes and vertical transport of particulate organic material in the pelagic environment, J. Plankion Res., 3, 369-387, 1981.

Welschmeyer, N. A., and C. J. Lorenzen, Chlorophyll budgets: Zooplankton grazing and phytoplankton growh in a temperate fjord and the central Pacific Ocean, Limnol. Oceanogr., 30, 1-21, 1986.

Wyriki, K., L. Magaard, and J. Hager, Eddy energy in the oceans, $J$. Geophys. Res., 81, 2641-2646, 1976.
T. D. Dickey, Ocean Physics Group, Department of Geological Sciences, University of Southem California, Los Angeles, CA 900890740.

T. C. Granata, Department of Biology, Southeastem Massachusetts University, North Dartmouth, MA 02747.

A. F. Michaels, Bermuda Biological Station for Research, Inc., 17 Biological Lane, Ferry Reach, GE 01, Bermuda.

D. A. Siegel, Department of Geography, 3611 Ellison Hall,

University of California at Santa Barbara, Santa Barbara, CA, 93106.

Received May 22, 1989.

revised July 27, 1989;

accepted September 27, 1989.) 